\title{
Revista Anales
}

Facultad de Ciencias Jurídicas y Sociales.

Universidad Nacional de La Plata-UNLP-

República Argentina

\section{CONFLICTO DE INTERESES Y DECLARACIÓN DE ORIGINALIDAD - AUTOR}

\section{CONFLICTO DE INTERESES- AUTOR}

El conflicto de intereses existe cuando el autor, revisor o editor tienen una relación financiera o personal que influye inapropiadamente en sus acciones (relaciones conocidas como doble compromiso, conflicto de intereses o lealtades en competencia).

La siguiente declaración debe ser presentada con el manuscrito al momento de la entrega, como un archivo adicional (uno por cada autor) que contenga la siguiente información:

Nombre y Apellido: María Mercedes Albornoz

Lugar y fecha: Ciudad de México, 30 de septiembre de 2021

Título del Artículo: Rigidez y flexibilidad: derecho aplicable a los contratos internacionales en ausencia de elección

Declaro que no existe ningún conflicto de intereses (económico, profesional o personal) real o potencial para la publicación de este Trabajo. De lo contrario, cada autor deberá declarar luego de su firma el conflicto de intereses.

\section{DECLARACIÓN DE ORIGINALIDAD- AUTOR}

La declaración de originalidad implica que el artículo no ha sido publicado previamente ni enviado a otras revistas para evaluación y se presenta conforme las Pautas editoriales e Instrucciones para los autores que se encuentran en la plataforma de la Revista.

Nombre y Apellido: María Mercedes Albornoz

Lugar y fecha: Ciudad de México, 30 de septiembre de 2021 


\section{Revista Anales}

Facultad de Ciencias Jurídicas y Sociales.

Universidad Nacional de La Plata-UNLP-

República Argentina

Título del Artículo: Rigidez y flexibilidad: derecho aplicable a los contratos internacionales en ausencia de elección

Declaro que el artículo enviado a la Revista Anales de la Facultad de Ciencias Jurídicas y Sociales de la Universidad Nacional de La Plata no ha sido publicado previamente ni enviado a otras revistas para evaluación. A su vez, el mismo cumple TODOS los criterios establecidos en las Pautas editoriales e Instrucciones para los autores, entre ellos el de originalidad.

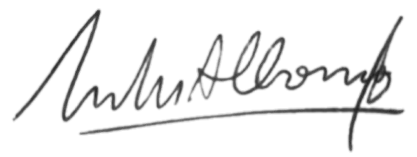

María Mercedes Albornoz 